\title{
ERROR BOUNDS FOR AFFINE FRACTAL INTERPOLATION
}

\author{
M. A. NAVAscués And M. V. SEbastián
}

Abstract. Fractal interpolation constitutes an advance in the techniques of approximation in the sense that the functions used are not necessarily differentiable and show the rough aspect of realworld signals. We prove here that the affine fractal interpolation functions play, for non-smooth functions, a role similar to polynomials for smooth functions. The affine fractal interpolation operator is studied and its linearity and continuity is proven. A sufficient condition for the convergence of this type of interpolant as the step tends to zero is also given. As a consequence, the density of affine fractal functions in the space of continuous functions is deduced. The error of interpolation is bounded in two ways, in terms of the scale factors of the transformation and by means of the Lebesgue constant of the associated partition. Finally, a general method of data fitting is proposed and the validity and convergence of the procedure is proven as well.

Mathematics subject classification (2000): 28A80, 58C05, 65D05, 65D10, 26A18.

Key words and phrases: fractal interpolation functions, iterated function systems.

\section{REFERENCES}

1] M. F. BARnSLEY, Fractals Everywhere, Academic Press, Inc. 1988.

[2] M. F. BARnsley, Fractal functions and interpolation, Constr. Approx., 2, (4) (1986), 303-329.

[3] E. W. CHENEY, Approximation Theory, AMS Chelsea Publ. 1966.

[4] P. J. DAVIS, Interpolation and Approximation, Dover 1963.

[5] Z. FENG, H. XIE, On stability of fractal interpolation, Fractals, 6, (3) (1998), 269-273.

[6] P. Massopust, Fractal functions and their applications, Chaos Solitons Fractals, 8, (2), (1997), 171-190.

[7] M. A. NAVAscues, M. V. SEBAStian, Generalization of Hermite functions by fractal interpolation, J. of Approx. Theory, 131, (1) (2004), 19-29.

[8] M. A. Navascues, M. V. Sebastian, Some results of convergence of spline fractal interpolation functions, Fractals, 11, (1) (2003), 1-7.

[9] M. A. NAVASCUES, M. V. SEBASTIAN, Fitting curves by fractal interpolation: an application of cognitive brain processes. In: Thinking in Patterns: Fractal and Related Phenomena in Nature. Novak M.M.(ed.), World Sci. 2004.

[10] S. CHEN, The non-differentiability of a class of fractal interpolation functions, Acta Math. Sci., 19, (4) (1999), 425-430.

[11] J. SZABADOS, P. VERTESI, Interpolation of functions, World Scientific. 1990.

[12] S. ZHEN, Hölder property of fractal interpolation functions, Approx. Theory Appl., 8, (4) (1992), 45-57. 